\title{
UNCIASSIFIED
}

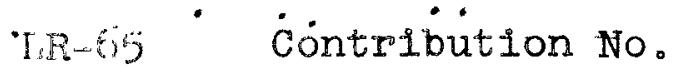

from the Institute for Atomic Research and Department of Chemistry, Iowa state College, Ames, Iowa. Work was performed in the Ames Laboratory of the Atomic Energy Commission.

\section{BACKSCATTERING OF BETA-RAYS IN WINDOWLESS GEIGER-MÜLLER COUNTERS}

Darleane Christian, Wayne W. Dunning and Don S. Martin, Jr.

\section{INTRODUCTION}

The windowless, gas-flow type Geiger-Müller counter is particularly useful in the detection of low energy betaparticles since absorption by the window and air are eliminated. As Graf, Comar and Whitney (1) have shown, the lower the beta energy to be measured the greater will be the advantage of a windowless counter over the conventional end-window counter. A counter tube operating in the Geiger region gives nearly - uniform pulses which are independent of the primary ionization. Thus a pulse may be initiated by a scattered beta-particle although it produces but a single ion pair in the counter gas. In this investigation counting rates corresponding to nearly 80 per cent of the radioactive disintegration rates were sometimes obtained when beta-emitters were introduced into a windowless Gelger-Müller counter。 Quite evidently scattering is important in the attainment of such high counting efficiencies. With conventional thin end-window counters (ca. $2 \mathrm{mg} / \mathrm{cm}^{2}$ ), efficiencies are usually no more than 10-15 per cent. In contrast to other counting arrangements, the counting rates obtalned in windowless counters are remarkably insensitive to 


\section{DISCLAIMER}

This report was prepared as an account of work sponsored by an agency of the United States Government. Neither the United States Government nor any agency Thereof, nor any of their employees, makes any warranty, express or implied, or assumes any legal liability or responsibility for the accuracy, completeness, or usefulness of any information, apparatus, product, or process disclosed, or represents that its use would not infringe privately owned rights. Reference herein to any specific commercial product, process, or service by trade name, trademark, manufacturer, or otherwise does not necessarily constitute or imply its endorsement, recommendation, or favoring by the United States Government or any agency thereof. The views and opinions of authors expressed herein do not necessarily state or reflect those of the United States Government or any agency thereof. 


\section{DISCLAIMER}

Portions of this document may be illegible in electronic image products. Images are produced from the best available original document. 
the precise geometrical arrangement of the source, so little attention need be given toward attaining an exactly reproducible placement of the source. The windowless G-M counter also offers some advantage over the corresponding proportional counter which requires more extensive electronic amplification with an arbitrary and not too reproducible discrimination or pulses with loss of counting rate.

Before absolute disintegration rates can be determined in a windowless counter, a knowledge of the backscattering factor Is necessary. Since no such data have been reported for the windowless Geiger-Müller counter, the backscattering for four beta-emitters by backing elements of various atomic numbers was investigated. For an end-window counter, the counting rate of a nearly weightless source on a thin plastic film can be used as the value for zero backscatterer. This value can then be compared with the counting rates resulting from placing the backscatterers directly behind the source. However, in a windowless flow counter, one cannot obtain the counting rate for zero backscatterer in this manner since the sample must always be placed directly on top of the base of the counter chamber.

A comparison has been made of the counting rates obtained in a windowless $G-M$ counter by placing radioactive deposits on the various backscatterers which were thick enough to give a limiting maximum value. (Engelkemier and co-workers (2) have shown that a thickness greater than $1 / 5$ of the beta-particle range suffices to give the maximum or saturation effect.) 
Na....tialf the absolute disintegration rate of the samples, if known, was used as the value for zero backscatterer. From the vardation of the counting rate with atomic number of the backscatterer, curves of counting efficiency versus atomic number were plotted for each beta-emitter investigated. The desired backscattering factors can then be read from these curves.

\section{EXPERIMENTAI PROCEDURE}

Windowless, gas folow Geiger-Mülier counter. In this work a one place windowless, gas flow $G-M$ counter manufactured by the No wood Co. was used. The counter operated at about 1300 volts. "Q" gas obtained from the Nuclear Instrument and Chemical Corporation was passed through the counter at a constant rate. A conventional scale of 64 scaler was used in conjunction with the counter. Multiple pulses were not abnormally frequent,

Activities used. Four different betamemitters wère used tos indicate variations which might be due to the beta-ray energies and possibly to the differences in the spectra. Table I Lists the pertinent data concerning the activities.

Materials used as backscatterers. Beryllium, magnesium, aluminum, nickel, copper, silver, tantalum and platinum metals were used as the backscattering elements. Discs about $2.5 \mathrm{~cm}$ In diameter and thick enough to insure saturation backscattering were used. Surfaces of the various metals had different characterastics; for example, the platinum was bright while the tantalum was ouite dull. All discs except the beryllium were cut from 
Table I 4

Characteristics of Beta-Emitters

\begin{tabular}{|c|c|c|c|c|c|}
\hline Activity & $T_{\frac{1}{2}}$ & $\begin{array}{c}\mathrm{E}_{\max } \text { of } \beta^{-} \\
\left(\mathrm{MeV}_{0}\right)\end{array}$ & $\begin{array}{l}\text { Specific } \\
\text { Activity } \\
\text { (d/m mg) }\end{array}$ & $\underset{\text { Chemf cal }}{\text { Chom }}$ & Source \\
\hline $\mathrm{Ni}^{63}$ & $85 y$ & 0.067 & $\begin{array}{c}5.3 \times 10^{8} \\
\left(50 \mathrm{yl}^{\mathrm{I}}=0.01 \mathrm{yg}\right)\end{array}$ & $\mathrm{NiCl}_{2}$ & $\begin{array}{c}\text { Oak Ridge } P 1 l e \\
\mathrm{~N} 1(\mathrm{n}, \gamma)\end{array}$ \\
\hline$s^{35}$ & $87 d$ & 0.17 & $\begin{array}{c}\text { no carrier } \\
(50 \mathrm{ml}=0.00 \mathrm{mg})\end{array}$ & $\mathrm{H}_{2} \mathrm{SO}_{4}$ & $\begin{array}{l}\text { Oak Ridge Pile } \\
\operatorname{Cl}(n, p)\end{array}$ \\
\hline $\mathrm{Co}^{60}$ & $5.3 y$ & 0.31 & $\begin{array}{c}5 \times 10^{7} \\
(50 \mu I=0.15 \mu g)\end{array}$ & $\mathrm{CoCl}_{2}$ & $\begin{array}{l}\text { Oak RIdge Pile } \\
\text { Co }(n, \gamma)\end{array}$ \\
\hline$p^{32}$ & $14.3 d$ & 1.7 & $\begin{array}{c}4.2 \times 10^{8} \\
\left(50 \mu I^{2}=0.02 \mu g\right)\end{array}$ & $\mathrm{H}_{3} \mathrm{PO}_{4}$ & $\begin{array}{l}\text { U. S. Bureau } \\
\text { of Standards } \\
S(n, p)\end{array}$ \\
\hline
\end{tabular}


commercial folls which were probably fabricated by rolilng. The beryllium discs ( $\mathrm{x}$-ray windowa) appeared to have been cut by an abrasive wheel from rod. The magnesium discs were etched with dilute $\mathrm{HCl}$ to remove oxide film.

Disintegration rate calibrations. $\mathrm{P}^{32}$ samples were call brated by comparison of counting rates with aliquots of a standard sample received from the National Bureau of Standards In Apri1, 1951. The disintegration rates of $\mathrm{Co}^{60}$ samples were obtained by comparison of their counting rates with a standard source which had been calibrated in this Laboratory by the coincidence-counting technique. The disintegration rate of the $\mathrm{P}^{32}$ standard was also calculated from a comparison of its counting rate with that of the $\mathrm{Co}^{60}$ standard with appropriate corrections for the energy dependence of absorption and scattering. A value 1.07 times the value taken from the Bureau of Standards data was obtained. Both B. P. Burtt (3) and $T$. Novey (4) have reported obtaining values 8 per cent higher for the absolute disintegration rate of $\mathrm{p}^{32}$ standards than the values given by the National Bureau of Standards. They suggested that the National Bureau of Standards value might be In error by 8 per cent because of self-scattering due to the finite thickness of the Ra D-Ra E standards which were used. Preparation of samples. In exploratory experiments $50 \mathrm{Ml}$ aliquots of the various active solutions were evaporated directly on the metal backscatterers. Two samples of each were prepared and counted. Yaffe (5) has reported that surface differences 
can influence counting rates. Consequently, in a second seroles of experiments the samples were prepared by evaporation of $50 \mathrm{M}^{1}$ aliquots of the activities on thin zapon films of about $30 \mathrm{Mg} / \mathrm{cm}^{2}$ thickness. The films were supported $1.0 \mathrm{~mm}$ above the surface of the metal backing by plastic rings $2.5 \mathrm{~cm}$ in diameter. The samples faced the sensitive volume of the counter.

\section{RESULTS AND DISCUSSION}

The results from the samples evaporated directly on the metals proved to be very erratic for $\mathrm{Ni}^{63}$ and $\mathrm{s}^{35}$. These erratic results may have been partially due to differences in the metal surfaces. The principal causes were probably the attack of the metals by the very dilute acld solutions with subsequent absorption of the radiation or an uneven distribution of the activity on the backscatterer with resulting differences in self-absorption. AII of these factors would be more important for the lower energy beta-emitters. However, the fact that tantalum consistently gave values which appeared slightly low in comparison to platinum and the other metals, may have been due to differences in the metal surface character.

The experimental results of the fllm experiments are shown in Figure 1. Some of the scattering of the observed points may be due to fluctuations in the efficiency of the counter itselfo Changes in atmospheric pressure and temperature may cause alterations in its counting characteristics. For Co 60 and $\mathrm{P}^{32}$ samples, one-half the absolute disintegration rato was taken as the 
counting rate for a backscatterer of zero atomic number. (The Bureau of standards value of the disintegration rate for $\mathrm{p}^{32}$ was used.) With $\mathrm{Co}^{60}$, the counting efficiency approached a limiting value of about 78 per cent for platinum backing $(z=78)$. The counting efficiency for $\mathrm{P}^{32}$ attained a similar value for platinum backing and it seems unlikely that significantly higher counting rates would be obtalned with heavier elements. Differences between the $\mathrm{co}^{60}$ and $\mathrm{s}^{35}$ curves were too small to be real. However, the counting efficiency for $\mathrm{N}^{63}$ approached a saturation value at significantly lower atomic numbers. From the shape of the curve there seems to be little doubt that the saturation value must be about $75-80$ per cent. Consequently, the counting data in Figure 1 for $\mathrm{s}^{35}$ and $\mathrm{N}^{63}$ have been converted to efficiencies by setting their saturation values equal to 78 per cent.

Counting efficiencies for thin radioactive samples may therefore be read directly from Figure 1 . Of particular value is the feature that with heavy element backings, 1.e., with platinum or tantalum, counting rates for thin samples in windowless counters are independent of the beta-ray energy over a wide range. Therefore, under these conditions disintegration rates can be taken as proportional to counting rates of aifferent beta-emitting radioactivities. 


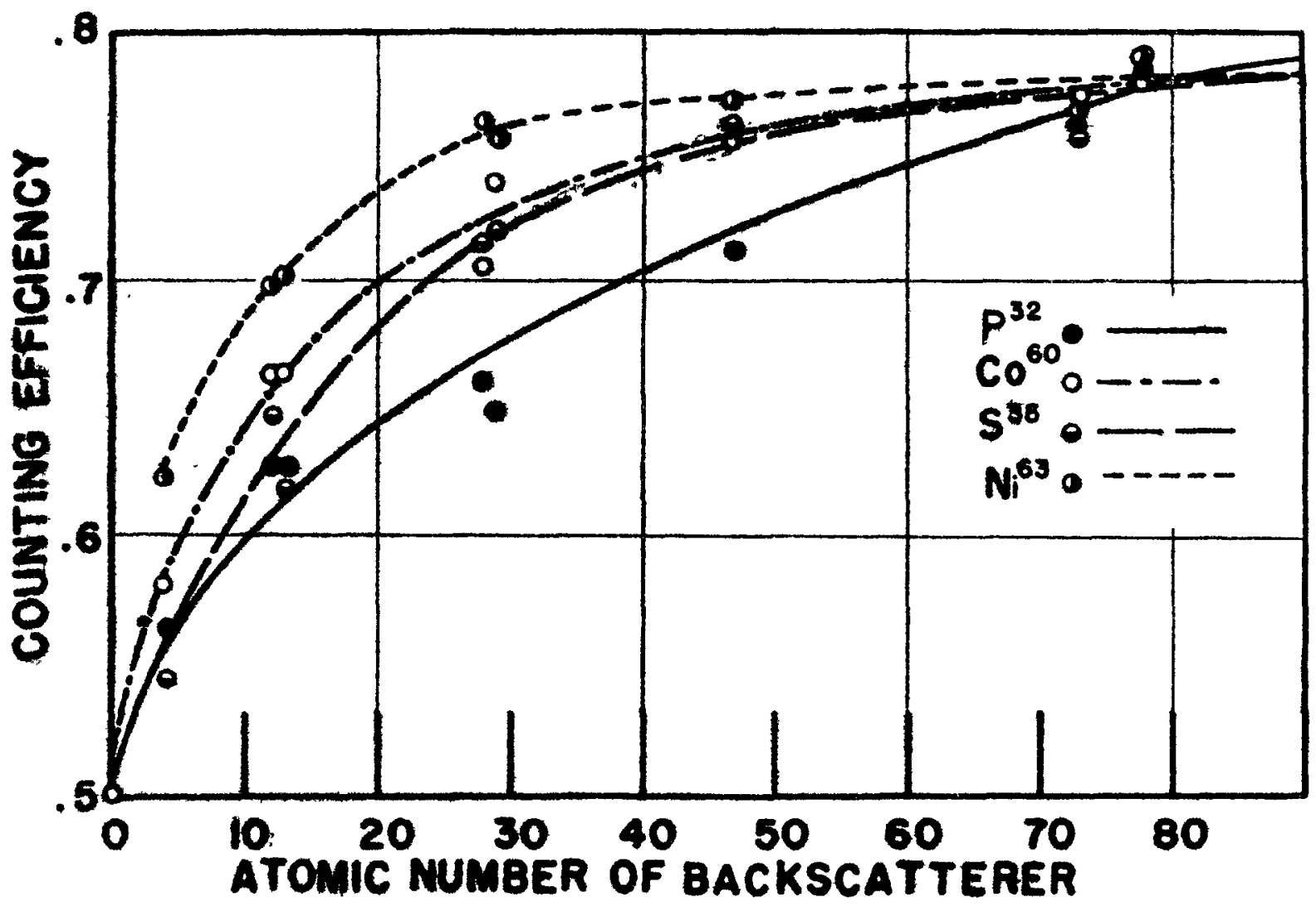

1
1
1
1
0

Fig。1。 Backscattering Curves for the Windowless Counter。 